Article

\title{
Clinical Evaluation of Stretchable and Wearable Inkjet-Printed Strain Gauge Sensor for Respiratory Rate Monitoring at Different Body Postures
}

\author{
Ala'aldeen Al-Halhouli ${ }^{1,2,3, * \mathbb{C}}$, Loiy Al-Ghussain ${ }^{1,4}{ }^{\mathbb{C}}$, Saleem El Bouri ${ }^{1}$, Fuad Habash ${ }^{1}$, \\ Haipeng Liu ${ }^{5,6}$ and Dingchang Zheng ${ }^{6}$ \\ 1 Mechatronics Engineering Department/NanoLab, School of Applied Technical Sciences, German Jordanian \\ University, P.O. Box 35247, Amman 11180, Jordan; loiy.al-ghussain@uky.edu (L.A.-G.); \\ saleem.bouri@hotmail.com (S.E.B.); f.habash@gju.edu.jo (F.H.) \\ 2 Institute of Microtechnology, Technische Universität Braunschweig, 38124 Braunschweig, Germany \\ 3 Faculty of Engineering, Middle East University, Amman 11831, Jordan \\ 4 Mechanical Engineering Department, University of Kentucky, Lexington, KY 40506, USA \\ 5 Medical Device and Technology Research Laboratory, School of Allied Health, Faculty of Health, Education, \\ Medicine and Social Care, Anglia Ruskin University, Chelmsford CM1 1SQ, UK; haipeng.liu@anglia.ac.uk \\ 6 Research Centre of Intelligent Healthcare, Faculty of Health and Life Science, Coventry University, \\ Coventry CV1 5FB, UK; dingchang.zheng@coventry.ac.uk \\ * Correspondence: alaaldeen.alhalhouli@gju.edu.jo
}

Received: 21 November 2019; Accepted: 11 December 2019; Published: 9 January 2020 updates

\begin{abstract}
Respiratory rate (RR) is a vital sign with continuous, convenient, and accurate measurement which is difficult and still under investigation. The present study investigates and evaluates a stretchable and wearable inkjet-printed strain gauge sensor (IJP) to estimate the RR continuously by detecting the respiratory volume change in the chest area. As the volume change could cause different strain changes at different body postures, this study aims to investigate the accuracy of the IJP RR sensor at selected postures. The evaluation was performed twice on 15 healthy male subjects (mean \pm SD of age: $24 \pm 1.22$ years). The RR was simultaneously measured in breaths per minute (BPM) by the IJP RR sensor and a reference RR sensor (e-Health nasal thermal sensor) at each of the five body postures namely standing, sitting at $90^{\circ}$, Flower's position at $45^{\circ}$, supine, and right lateral recumbent. There was no significant difference in measured RR between IJP and reference sensors, between two trials, or between different body postures (all $p>0.05$ ). Body posture did not have any significant effect on the difference of RR measurements between IJP and the reference sensors (difference $<0.01 \mathrm{BPM}$ for each measurement in both trials). The IJP sensor could accurately measure the RR at different body postures, which makes it a promising, simple, and user-friendly option for clinical and daily uses.
\end{abstract}

Keywords: inkjet printing; respiratory rate; strain gauge; stretchable and wearable sensors; silver nanoparticles; clinical evaluation; body posture

\section{Introduction}

Clinically, respiratory rate (RR), defined as the times of breath per minute (BPM), is a vital sign whose abnormality could indicate various pathological conditions in cardiorespiratory system [1,2]. Compared with other vital signs such as heart rate and blood pressure, $\mathrm{RR}$ is more accurate in screening unstable patients [1,3,4]. Therefore, RR monitoring has been used in detecting sleep apnea, cardiac arrest, and sudden infant death syndrome [3,5]. Especially, compared with discrete RR measurement, continuous RR monitoring could detect RR abnormalities with more than 10 times of accuracy [2]. 
However, despite the clinical significance of RR, continuous, convenient, and accurate RR monitoring is still difficult. It was reported in [2] that the RR was the least documented vital sign even when the patients suffered from respiratory issues. Manual RR counting is widely used in clinical examination [3] but is not accurate [2]. Other traditional techniques of clinical RR monitoring include spirometry, pneumotachograph, and capnography $[1,4,6]$. These techniques could accurately measure $\mathrm{RR}$, but are cumbersome, difficult to manipulate, or mask-based [4].

To achieve continuous and convenient RR monitoring, some new techniques have been developed [7-10]. Some researchers extract RR from other physiological signals such as photoplethysmogram and electrocardiogram [11]. Other studies derived respiration signals using non-contact techniques such as C-band sensing [12] and dual smartphone cameras [4]. Some researchers tried distant (less than $10 \mathrm{~m}$ ) RR detecting based on Wi-Fi, radar, or thermal imaging [11]. Compared with these techniques, wearable and stretchable sensors could independently measure RR without limiting the daily activities of the users. Additionally, the stretchable and wearable sensors could achieve highly accurate RR measurement at a low cost [13].

For a wearable RR sensor, the high accuracy at different body postures could enable its application in various clinical and daily situations. Several studies $[3,12,14]$ have investigated the accuracy of RR monitoring devices at different body postures (sitting, standing and supine and side). For instance, Huang et al. [3] embedded arrays of load sensors in an e-textile bed sheet to measure RR from the full body pressure distribution on the sheet. The sensor was tested on 14 human subjects in prone, side and supine postures during sleep. The results showed that RR measurement was more accurate in prone and supine postures compared with side posture. The authors deduced that this difference was due to the amplitude of respiratory movement which is more prominent in thoracic and abdominal areas than on both sides. Zhu et al. [14] developed a fiber bragg grating (FBG) sensor mat with three FBG arrays under the pillow, below upper chest, and below lower chest. The sensor was tested on 12 human subjects while lying in prone and side postures. For each of the three sensors, the mean error of RR measurement was lower than one BPM with standard deviation (STD) within \pm 0.25 BPM, compared with the reference RR measured by a polysomnography belt sensor. Guan et al. [12] developed a wireless system to measure RR based on C-band sensing. In prone, sitting, and standing postures, the error of RR detection was within $7 \%, 6.2 \%$ and $5.5 \%$ compared with a reference RR sensor. The author suggested that standing posture have the largest influence on the quality of C-band RR detection. Nam et al. [4] used dual cameras on a smartphone to measured RR by reflectance imaging on the chest and the abdomen, with average median error of $1.43 \%$ and $1.62 \%$.

The majority of existing studies on the effect of body posture on RR detection accuracy were based on non-stretchable [15-17] or non-wearable RR sensors [3,12,14], with a lack of related study based on stretchable RR sensors. Compared with traditional RR sensors, stretchable RR sensors are in direct contact with body surface, and are therefore, more likely to be influenced by body posture. Considering the increasing amount of stretchable RR sensors and the possibility of application in different scenarios, there is an urgent need to investigate the effect of body posture on the accuracy of stretchable RR sensors.

The aim of this paper is to investigate the effect of different body postures (standing, sitting at $90^{\circ}$, Flower's position at $45^{\circ}$, supine and right lateral recumbent) on the accuracy of a new stretchable and wearable inkjet-printed RR sensor.

\section{Methods}

\subsection{Physiological Measurements}

\subsubsection{Subjects}

Fifteen healthy male subjects (mean \pm SD of age: $24 \pm 1.22$ years) without any known cardiovascular or respiratory diseases participated in this study with written informed consent. The protocol adhered 
to the tenets of the Declaration of Helsinki. Before the experiment, the procedure was explained in detail to each subject.

\subsubsection{Sensors}

Inkjet printing (IJP) is a promising technology in the fabrication of stretchable and wearable sensors. Compared with other fabrication techniques, IJP has less sophisticated process and lower cost [18-21]. The IJP RR sensor was fabricated on polydimethylsiloxane (PDMS) substrate using conductive silver nanoparticle ink, as shown in Figure 1a which was presented in [22]. During respiration, the sensor acted as a variable resistance whose value increased during inhalation and decreased during exhalation, due to the volume change in the ribcage or the abdomen. The change in resistance was obtained by a Wheatstone bridge circuit with three fixed resistances, amplified by an instrumentational amplifier, and finally fed into an Arduino microcontroller to derive RR.

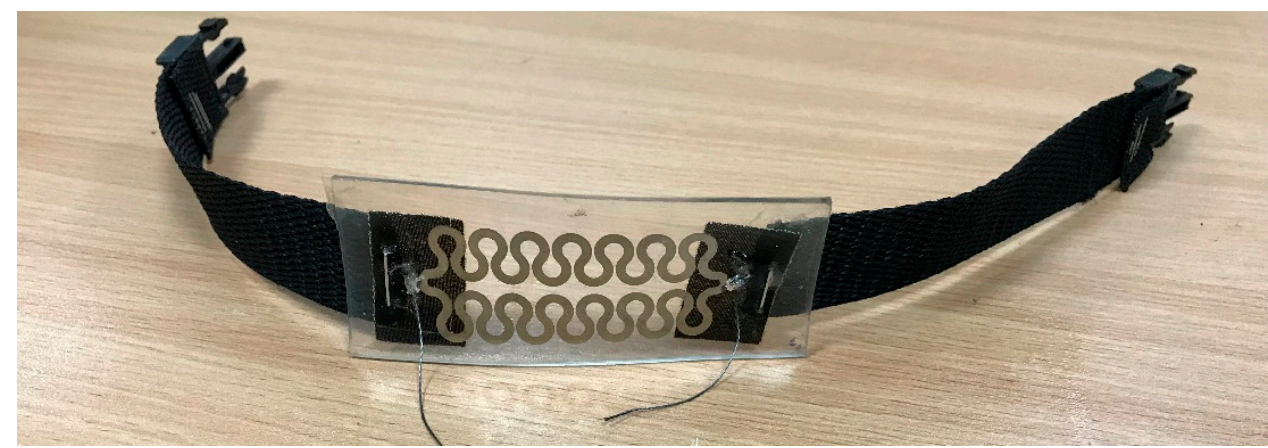

(a)

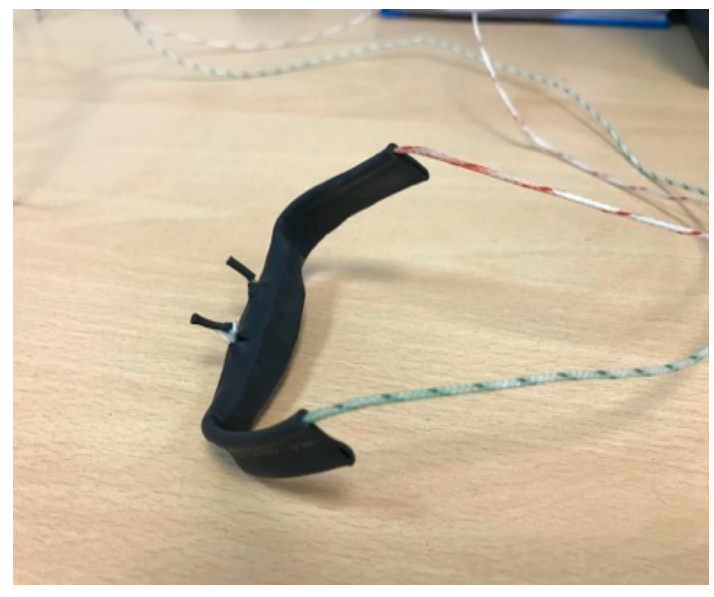

(b)

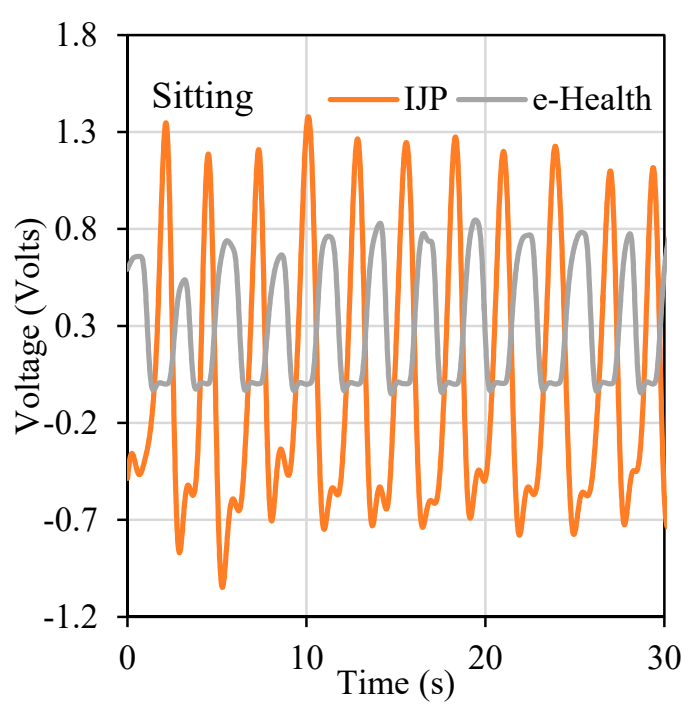

(c)

Figure 1. (a) The Inkjet printing (IJP) respiration rate (RR) sensor. (b) The reference e-Health RR sensor. (c) The derived respiratory signals in $30 \mathrm{~s}$.

The reference RR value was measured by a thermal nasal e-Health sensor (e-Health AirFlow sensor, Cooking Hacks), shown in Figure 1b, which has been validated previously in the literature [23,24]. The e-Health sensor detects the thermal changes in airflow during inhalation and exhalation. Due to the difference in working principle between IJP and reference RR sensors, their respiratory signals fluctuated in opposite directions with a phase shift, as shown in Figure 1c. 


\subsubsection{Measurement Procedure}

During the measurement, the IJP sensor was mounted at the xiphoid process using adjustable fabric belt with e-Health sensor mounted at the nostril as shown in Figure 2. The IJP sensor was tested at five different body postures in randomized order: sitting at $90^{\circ}, 45^{\circ}$ Fowler's position, standing, supine, and right lateral recumbent, as shown in Figure 3. In the lateral recumbent, Flower's position and supine, the test subjects had their heads resting on a pillow. Only the right lateral recumbent was included without the left one, because the bilateral respiratory movements have been proved to be similar [25]. At each posture, the test was repeated twice in order to investigate the repeatability. The $\mathrm{RR}$ recording lasted for one minute in each trial, with a $60 \mathrm{~s}$ break between the two trials. The test subjects were asked not to move during the test and to breathe normally.

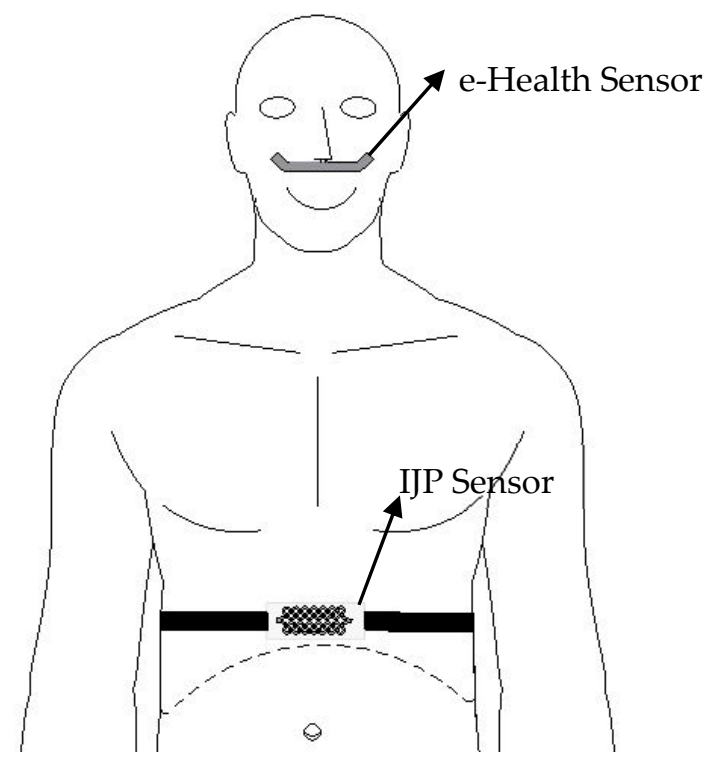

Figure 2. Mounting the IJP sensor at the xiphoid process using adjustable belt and the e-Health sensor at nostril.

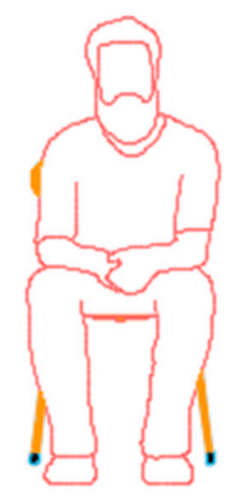

Sitting at $90^{\circ} \mathrm{C}$

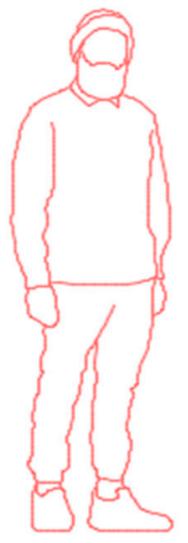

Standing

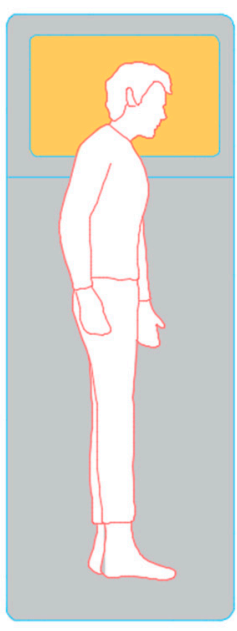

Lateral Recumbent

Figure 3. Cont. 


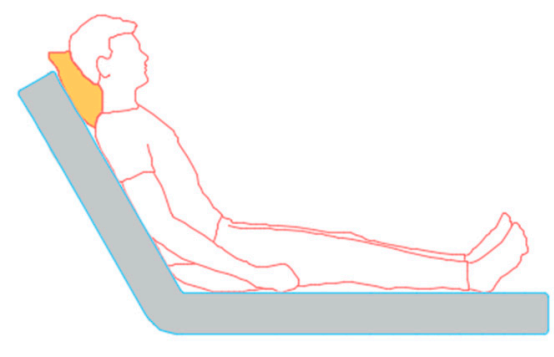

$45^{\circ}$ Fowler's

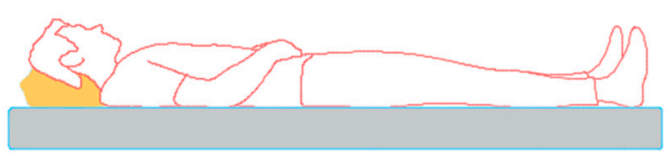

Supine

Figure 3. The RR measurement at different body postures.

\subsection{Respiratory Rate Derivation}

An algorithm was developed on MATLAB (R2018b, MathWorks Inc., Natick, MA, USA) to extract the RR values from the respiratory signals. Firstly, raw data were input into the bridge circuit at a sampling frequency of $100 \mathrm{~Hz}$. The signal was then filtered to remove the direct current (DC) component and some extremely high and low frequencies using a band-pass filter with lower and higher cut-off frequencies of $0.05 \mathrm{~Hz}$ and $1.5 \mathrm{~Hz}$. Finally, fast Fourier transform (FFT) was used to determine the respiration frequency, which is the frequency with the highest amplitude. RR was derived as: $R R=60 \times$ respiratory frequency. Figure 4 shows the derivation procedure of the RR from the IJP sensor. Note in Figure 4 that the sharp peak is considered as noise since it exceeds the amplitudes of adjacent respiratory cycles with time period of less than $0.1 \mathrm{~s}$, which is impossible for a respiratory cycle even for maximum inhalation or exhalation [11].

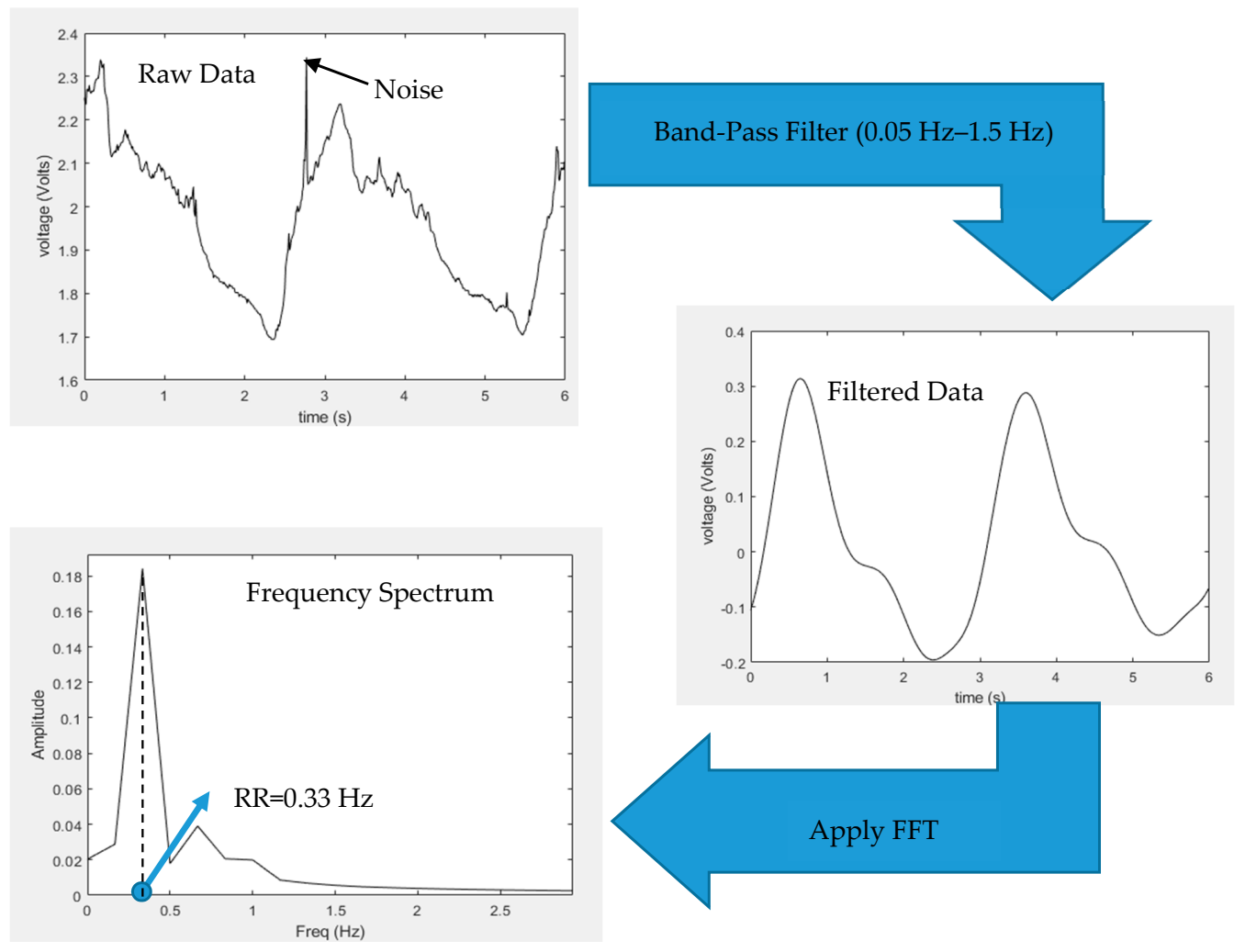

Figure 4. RR derivation flow chart from the IJP sensor. The raw data was input into band-pass filter to filter out the high frequencies and the noise. The RR was then extracted by Simulink (R2018b, MathWorks Inc., Natick, MA, USA). The arrow in the first subfigure shows the spike caused by noise. 


\subsection{Statistical Analysis}

The statistical analysis was performed on SPSS (Version 20, SPSS Inc., Chicago, IL, USA). Firstly, to investigate if the RR measurement was significantly influenced by body postures, repeated trials, and different sensors, analysis of variance (ANOVA) was performed with Levene's test to validate the homogeneity of variance. Significance was defined as $p$-value less than 0.05 . To further investigate the effect of body posture on the measurement accuracy, the difference between RR values derived by IJP sensor and reference sensor was calculated for each measurement in different postures. Moreover, post hoc test based on Tukey's test was used to evaluate the statistical significance of the RR between any two postures to figure out the effect of the posture on the RR.

\section{Results}

As shown in Figure 5, in each trial and posture, IJP and reference RR sensors derived nearly identical distributions of RR. The details are listed in Table A1, Appendix A. The Levene's test showed that the dataset satisfied the homogeneity of variance $(p>0.05)$. Hence, ANOVA was performed on $R R$ values. The results showed no significant differences in measured RR between IJP and reference sensors, between two measurement trials, and among different body postures (all $p>0.05$ ). Moreover, post hoc test showed no significant difference in the RR between any two posture (all $p>0.05$ ).
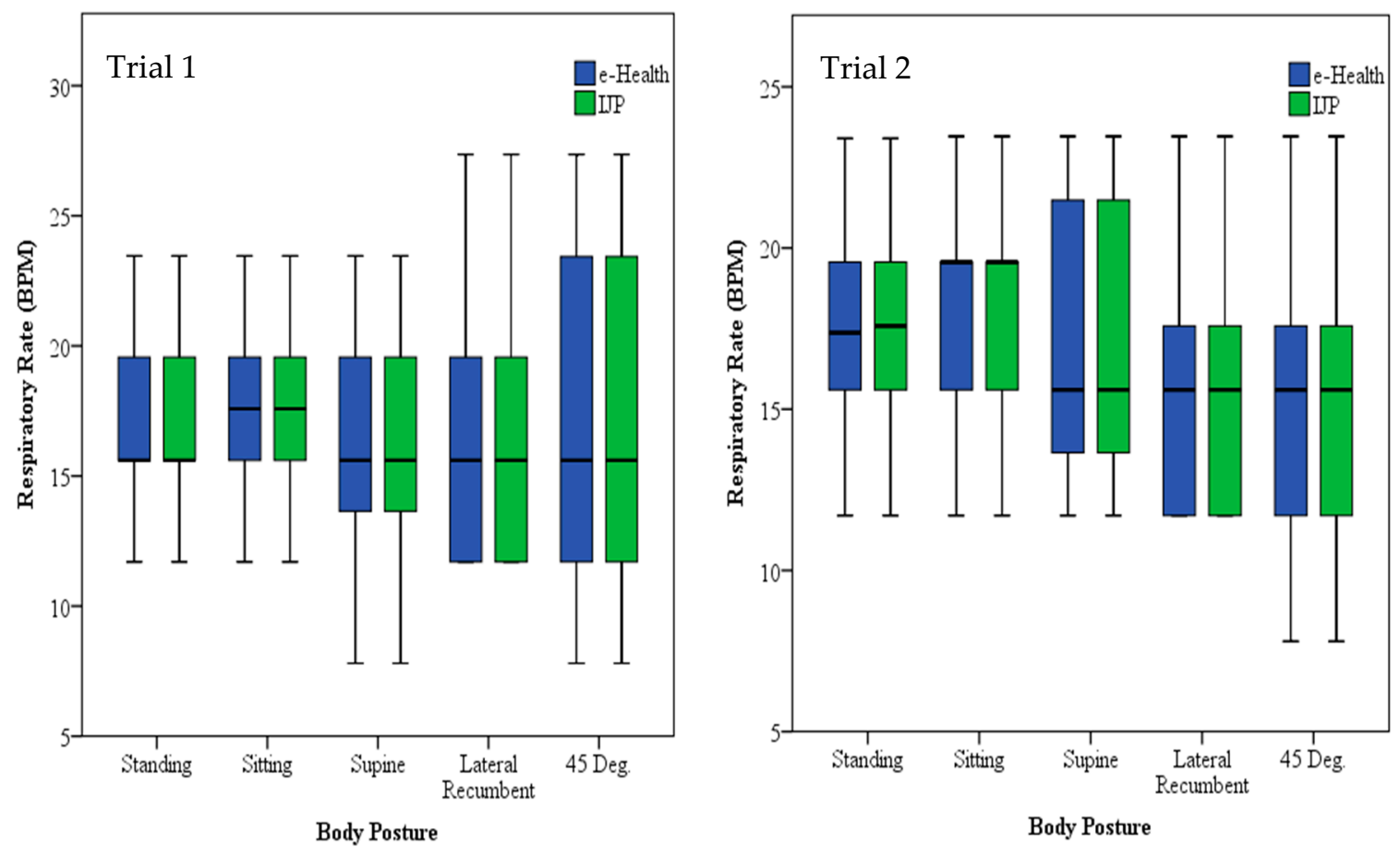

Figure 5. Box and whisker plots of the RR measured by the IJP sensor and the e-Health sensor for each trial at different body postures. The means are represented by the horizontal lines within the boxes while the first and third quartiles are represented by the boxes boundaries whereas the maximum and minimum values are represented by the whiskers.

\section{Discussion}

\subsection{IJP Sensor Accuracy: Comparison with Other Sensors}

The ANOVA results showed that IJP sensor had high accuracy, good repeatability, and stability at different body postures. With no observable deviation from the reference sensor at all body postures, the accuracy of the IJP sensor was better than many sensors reported in the literature where the RR 
measured by stretchable sensor deviated from the reference value from $1.7 \%$ to more than $6 \%$ in different postures $[4,12,26-30]$.

\subsection{RR Measurements at Different Body Postures}

The body posture could significantly influence the lung volume [12,31-33] and the consequent RR detection. The lung has the largest volume capacity at the sitting posture [31]. In lateral recumbent posture, lung and chest wall compliances decrease, which limits the amplitude of thoracic respiration movement [25]. Small respiratory movement amplitude could result in miscounting of RR. In stretchable RR sensors, due to the difference in strain between different postures, the accuracy of RR could be different.

However, in this study, IJP sensor showed high accuracy at different postures. Firstly, the skin-like characteristics of the PDMS surface allow the IJP sensor to closely attach to the body surface and follow the topographical changes [34,35]. Secondly, the polymer-based strain gauge sensors are very sensitive (gauge factor $>100$ ) compared with typical strain gauge ( $2 \leq$ gauge factor $\leq 5)$. Thirdly, silver nanoparticles are highly sensitive which increased the accuracy of the IJP sensor [36]. Finally, during the measurement, test subjects did not move, talk or laugh, which largely reduced the movement artefact in respiratory signals.

\subsection{Application of the IJP Sensor}

In addition to its accuracy, the IJP sensor is a low-cost sensor with skin-like characteristics that enhances the wearability of the sensor without limiting the daily activities of the patients. All the aforementioned characteristics of the IJP sensor makes it suitable for remote and continuous RR monitoring in low-resources settings and refugee camps, decreasing the pressure on the healthcare facilities in these settings which suffer from limited healthcare resources [37]. Continuous RR measurement in different postures is clinically significant especially for the monitoring of hospitalized patients. Currently, the RR monitoring relies on inaccurate manual counting in a short period (often 30 $\mathrm{s}$ or $1 \mathrm{~min}$ ) or is neglected [38]. The mask-based or contact RR sensors, such as the e-Health sensor in this study, could cause uncomfortableness which makes them inappropriate for long-term continuous RR monitoring. The IJP sensor could accurately and continuously measure RR without any skin allergy or other clinical events, which makes it possible for clinical use. RR measurement at different body postures is important for patients with different physiological conditions. For example, some patients under physiotherapy or with plastic cast need to keep in mainly supine or lateral recumbent postures. Therefore, the IJP sensor provides the possibility of continuous RR monitoring in different patients.

The IJP RR sensor is also applicable for RR monitoring at home without disturbing the users' daily activities. Wearable sensors could provide RR monitoring during the night at the supine and lateral position to inspect the sleep quality and contribute in early diagnostic of several sleep-related issues such as sleep apnea and insomnia [39]. Moreover, such wearable sensors could be used to reduce sudden infant death syndrome by providing comfortable and continuous RR monitoring [40]. Additionally, wearable sensors can be integrated into safety belts in automobiles which eases the monitoring of the RR during driving [11,41]. The IJP sensor accurately measured the RR at all the inspected postures which paved the way for its further application in daily life.

\subsection{Limitations and Future Work}

The evaluation of the sensor was performed on 15 healthy male subjects only. Firstly, scale-up validation was needed. Secondly, to eliminate the error caused by movement artefact, the IJP sensor was firmly fixed on the xiphoid process. In different body positions, the sensitivity to posture change might be different, which needs further investigation. Thirdly, the evaluation of wider age groups and genders could be performed to investigate if the IJP sensor is suitable for people with different physiological conditions. Furthermore, the study was performed on healthy subjects. The performance of the sensor on subjects with pathological conditions needs further investigation. The IJP sensor is a 
low-cost and wearable sensor that provides the possibility of daily RR monitoring. However, motion artefact is a major concern regarding the accuracy of RR monitoring during daily activities [11]. For the further application especially in daily healthcare monitoring, full validation on different levels of motion artefact is needed. Finally, more comfortable mounting mechanism such as the use of biocompatible and skin-friendly adhesive should be investigated.

\section{Conclusions}

The IJP sensor was able to measure the RR accurately at the five postures (standing, sitting at $90^{\circ}$, Flower's position at $45^{\circ}$, supine and right lateral recumbent), with good repeatability which makes it user-friendly, and very convenient for clinical practices with minimal user efforts and training needs. This IJP sensor is promising for continuous RR monitoring in different clinical and daily situations.

Author Contributions: Conceptualization, A.A.-H., L.A.-G., S.E.B., H.L., and D.Z.; methodology, L.A.-G., H.L., and D.Z.; software, S.E.B..; validation, S.E.B., L.A.-G. and F.H.; formal analysis, L.A.-G., S.E.B., H.L.; investigation, L.A.-G.; resources, A.A.-H., D.Z.; data curation, S.E.B. and F.H.; writing-original draft preparation, L.A.-G., S.E.B.; writing-review and editing, L.A.-G., H.L., A.A.-H.; visualization, L.A.-G.; supervision L.A.-G., H.L., D.Z. and A.A.-H.; project administration, A.A.-H. and L.A.-G.; funding acquisition, A.A.-H. and D.Z. All authors have read and agreed to the published version of the manuscript.

Funding: This research was funded by the Royal Academy of Engineering under grant Ref. IAPP1R2\100204.

Acknowledgments: The authors would like to thank the Royal Academy of Engineering for Funding this project under grant Ref. IAPP1R2 \100204. Moreover, the authors would like to thank the Industrial Research and Development Fund in the Higher Council for Science and Technology for their support of the project. In addition, the authors would like to thank Eng. Ali Al-Ghussein from the GJU Innovation and Entrepreneurship laboratory for providing the e-Health sensor.

Conflicts of Interest: The authors declare no conflict of interest.

\section{Appendix A}

Table A1. Average RR (breaths per minute, BPM) measured by the IJP and e-Health sensors at five different body postures.

\begin{tabular}{cccccccccccc}
\hline \multirow{2}{*}{ Gender } & Age & \multicolumn{2}{c}{ Standing } & \multicolumn{2}{c}{ Sitting } & \multicolumn{2}{c}{ 45 Deg. } & \multicolumn{2}{c}{ Supine } & \multicolumn{2}{c}{ Lateral } \\
\cline { 3 - 11 } & & Our & Ref & Our & Ref & Our & Ref & Our & Ref & Our & Ref \\
\hline M & 24 & 11.7 & 11.7 & 13.65 & 13.65 & 11.7 & 11.7 & 15.6 & 15.6 & 11.7 & 11.7 \\
M & 23 & 21.51 & 21.51 & 21.51 & 21.51 & 17.58 & 17.58 & 19.56 & 19.56 & 23.46 & 23.46 \\
M & 25 & 21.48 & 21.48 & 21.51 & 21.51 & 23.46 & 23.46 & 21.51 & 21.51 & 19.56 & 19.56 \\
M & 25 & 19.56 & 19.56 & 19.56 & 19.56 & 17.58 & 17.58 & 15.63 & 15.63 & 15.6 & 15.6 \\
M & 23 & 17.58 & 17.58 & 21.51 & 21.51 & 13.65 & 13.65 & 21.51 & 21.51 & 17.58 & 17.58 \\
M & 24 & 15.6 & 15.6 & 13.65 & 13.65 & 11.7 & 11.7 & 13.65 & 13.65 & 11.7 & 11.7 \\
M & 24 & 13.65 & 13.65 & 13.65 & 13.65 & 9.75 & 9.75 & 9.75 & 9.75 & 11.7 & 11.7 \\
M & 23 & 23.4 & 23.4 & 23.4 & 23.4 & 23.4 & 23.4 & 23.4 & 23.4 & 23.4 & 23.4 \\
M & 26 & 15.6 & 15.6 & 17.58 & 17.58 & 15.6 & 15.6 & 15.6 & 15.6 & 17.58 & 17.58 \\
M & 21 & 19.56 & 19.35 & 19.56 & 19.56 & 21.51 & 21.51 & 19.56 & 19.56 & 19.56 & 19.56 \\
M & 25 & 17.58 & 17.58 & 19.56 & 19.56 & 19.53 & 19.53 & 17.58 & 17.58 & 15.6 & 15.6 \\
M & 24 & 23.46 & 23.46 & 29.31 & 29.31 & 23.46 & 23.46 & 23.46 & 23.46 & 19.53 & 19.53 \\
M & 24 & 7.8 & 7.8 & 9.75 & 9.75 & 9.75 & 9.75 & 11.7 & 11.7 & 11.7 & 11.7 \\
M & 22 & 15.6 & 15.6 & 15.6 & 15.6 & 11.7 & 11.7 & 9.75 & 9.75 & 11.7 & 11.7 \\
M & 24 & 17.58 & 17.58 & 17.58 & 17.58 & 15.6 & 15.6 & 15.6 & 15.6 & 13.65 & 13.65 \\
\hline
\end{tabular}

\section{References}

1. AL-Khalidi, F.Q.; Saatchi, R.; Burke, D.; Elphick, H.; Tan, S. Respiration rate monitoring methods: A review. Pediatr. Pulmonol. 2011, 46, 523-529. [CrossRef] [PubMed]

2. Lee, P.J. Clinical evaluation of a novel respiratory rate monitor. J. Clin. Monit. Comput. 2016, 30, $175-183$. [CrossRef] [PubMed] 
3. Huang, M.; Xu, W.; Liu, J.; Samy, L.; Vajid, A.; Alshurafa, N.; Sarrafzadeh, M. Inconspicuous on-bed respiratory rate monitoring. In Proceedings of the 6th International Conference on PErvasive Technologies Related to Assistive Environments, Rhodes, Greece, 29-31 May 2013; ACM Press: New York, NY, USA, 2013; pp. 1-8.

4. Nam, Y.; Kong, Y.; Reyes, B.; Reljin, N.; Chon, K.H. Monitoring of Heart and Breathing Rates Using Dual Cameras on a Smartphone. PLoS ONE 2016, 11, e0151013. [CrossRef]

5. Sharma, H.; Sharma, K.K. ECG-derived respiration using Hermite expansion. Biomed. Signal Process. Control 2018, 39, 312-326. [CrossRef]

6. Di Fiore, J.M. Neonatal cardiorespiratory monitoring techniques. Semin. Neonatol. 2004, 9, $195-203$. [CrossRef] [PubMed]

7. Koch, E.; Dietzel, A. Stretchable sensor array for respiratory monitoring. In Proceedings of the 2017 19th International Conference on Solid-State Sensors, Actuators and Microsystems (TRANSDUCERS), Kaohsiung, Taiwan, 18-22 June 2017; pp. 2227-2230.

8. Jeong, J.W.; Jang, Y.W.; Lee, I.; Shin, S.; Kim, S. Wearable Respiratory Rate Monitoring using Piezo-resistive Fabric Sensor. In World Congress on Medical Physics and Biomedical Engineering, 7-12 September 2009, Munich, Germany; Dössel, O., Schlegel, W.C., Eds.; Springer: Berlin/Heidelberg, Germany, 2009; pp. 282-284. ISBN 978-3-642-03904-1.

9. Ciocchetti, M.; Massaroni, C.; Saccomandi, P.; Caponero, M.; Polimadei, A.; Formica, D.; Schena, E. Smart Textile Based on Fiber Bragg Grating Sensors for Respiratory Monitoring: Design and Preliminary Trials. Biosensors 2015, 5, 602-615. [CrossRef] [PubMed]

10. Chu, M.; Nguyen, T.; Pandey, V.; Zhou, Y.; Pham, H.N.; Bar-Yoseph, R.; Radom-Aizik, S.; Jain, R.; Cooper, D.M.; Khine, M. Respiration rate and volume measurements using wearable strain sensors. NPJ Digit. Med. 2019, 2, 8. [CrossRef]

11. Liu, H.; Allen, J.; Zheng, D.; Chen, F. Recent development of respiratory rate measurement technologies. Physiol. Meas. 2019, 40, 07TR01. [CrossRef]

12. Guan, H.; Yang, X.; Sun, W.; Ren, A.; Fan, D.; Zhao, N.; Guan, L.; Haider, D.; Abbasi, Q. Posture-Specific Breathing Detection. Sensors 2018, 18, 4443. [CrossRef]

13. Furtak, N.T.; Skrzetuska, E. Development of Screen-Printed Breathing Rate Sensors. FIBRES Text. East. Eur. 2013, 6, 84-88.

14. Zhu, Y.; Maniyeri, J.; Fook, V.F.S.; Zhang, H. Estimating respiratory rate from FBG optical sensors by using signal quality measurement. In Proceedings of the 2015 37th Annual International Conference of the IEEE Engineering in Medicine and Biology Society (EMBC), Milan, Italy, 25-29 August 2015; pp. 853-856.

15. Wu, D.; Wang, L.; Zhang, Y.; Huang, B.; Wang, B.; Lin, S.; Xu, X. A wearable respiration monitoring system based on digital respiratory inductive plethysmography. In Proceedings of the 2009 Annual International Conference of the IEEE Engineering in Medicine and Biology Society, Minneapolis, MN, USA, 3-6 September 2009; pp. 4844-4847.

16. Hesse, M.; Christ, P.; Hormann, T.; Ruckert, U. A respiration sensor for a chest-strap based wireless body sensor. In Proceedings of the IEEE SENSORS 2014 Proceedings, Valencia, Spain, 2-5 November 2014; pp. 490-493.

17. Sun, X.; Qiu, L.I.; Wu, Y.; Tang, Y.; Cao, G.; State, T.P. SleepMonitor: Monitoring Respiratory Rate and Body Position During Sleep Using Smartwatch. PACM Interact. Mob. Wearable Ubiquitous Technol. 2017, 13, 104. [CrossRef]

18. Al-Halhouli, A.; Qitouqa, H.; Alashqar, A.; Abu-Khalaf, J. Inkjet printing for the fabrication of flexible/stretchable wearable electronic devices and sensors. Sens. Rev. 2018, 38, 438-452. [CrossRef]

19. Abu-Khalaf, J.; Al-Ghussain, L.; Al-Halhouli, A. Fabrication of Stretchable Circuits on Polydimethylsiloxane (PDMS) Pre-Stretched Substrates by Inkjet Printing Silver Nanoparticles. Materials 2018, 11, 2377. [CrossRef] [PubMed]

20. Abu-khalaf, J.M.; Saraireh, R.; Eisa, S.M.; Al-halhouli, A. Experimental Characterization of Inkjet-Printed Stretchable Circuits for Wearable Sensor Applications. Sensors 2018, 18, 3476. [CrossRef] [PubMed]

21. Abu-khalaf, J.M.; Al-Ghussain, L.; Nadi, A.; Saraireh, R.; Rabayah, A.; Altarazi, S.; Al-Halhouli, A. Optimization of Geometry Parameters of Inkjet-Printed Silver Nanoparticle Traces on PDMS Substrates Using Response Surface Methodology. Materials 2019, 12, 3329. [CrossRef] 
22. Al-Halhouli, A.; Al-Ghussain, L.; El Bouri, S.; Liu, H.; Zheng, D. Fabrication and Evaluation of a Novel Non-Invasive Stretchable and Wearable Respiratory Rate Sensor Based on Silver Nanoparticles Using Inkjet Printing Technology. Polymers 2019, 11, 1518. [CrossRef]

23. Bayo-Monton, J.L.; Martinez-Millana, A.; Han, W.; Fernandez-Llatas, C.; Sun, Y.; Traver, V. Wearable Sensors Integrated with Internet of Things for Advancing eHealth Care. Sensors 2018, 18, 1851. [CrossRef]

24. Rákay, R.; Višňovský, M.; Galajdová, A.; Šimšík, D. Testing Properties of E-health System Based on Arduino. J. Autom. Control. 2015, 3, 122-126.

25. Mezidi, M.; Guérin, C. Effects of patient positioning on respiratory mechanics in mechanically ventilated ICU patients. Ann. Transl. Med. 2018, 6, 384. [CrossRef]

26. Turnbull, H.; Kasereka, M.C.; Amirav, I.; Sahika, S.E.; Solomon, I.; Aldar, Y.; Hawkes, M.T. Development of a novel device for objective respiratory rate measurement in low-resource settings. BMJ Innov. 2018, 4, 185-191. [CrossRef]

27. Jarchi, D.; Salvi, D.; Tarassenko, L.; Clifton, D. Validation of Instantaneous Respiratory Rate Using Reflectance PPG from Different Body Positions. Sensors 2018, 18, 3705. [CrossRef] [PubMed]

28. Van Loon, K.; Breteler, M.J.M.; van Wolfwinkel, L.; Rheineck Leyssius, A.T.; Kossen, S.; Kalkman, C.J.; van Zaane, B.; Peelen, L.M. Wireless non-invasive continuous respiratory monitoring with FMCW radar: A clinical validation study. J. Clin. Monit. Comput. 2016, 30, 797-805. [CrossRef] [PubMed]

29. Guechi, Y.; Pichot, A.; Frasca, D.; Rayeh-Pelardy, F.; Lardeur, J.-Y.; Mimoz, O. Assessment of noninvasive acoustic respiration rate monitoring in patients admitted to an Emergency Department for drug or alcoholic poisoning. J. Clin. Monit. Comput. 2015, 29, 721-726. [CrossRef] [PubMed]

30. Shen, C.-L.; Huang, T.-H.; Hsu, P.-C.; Ko, Y.-C.; Chen, F.-L.; Wang, W.-C.; Kao, T.; Chan, C.-T. Respiratory Rate Estimation by Using ECG, Impedance, and Motion Sensing in Smart Clothing. J. Med. Biol. Eng. 2017, 37, 826-842. [CrossRef] [PubMed]

31. Moreno, F.; Lyons, H.A. Effect of body posture on lung volumes. J. Appl. Physiol. 2017, 16, 27-29. [CrossRef] [PubMed]

32. Leipälä, J.A.; Bhat, R.Y.; Rafferty, G.F.; Hannam, S.; Greenough, A. Effect of posture on respiratory function and drive in preterm infants prior to discharge. Pediatr. Pulmonol. 2003, 36, 295-300. [CrossRef] [PubMed]

33. Pal, A.K. Effect of Recumbent Body Positions on Dynamic Lung Function Parameters in Healthy Young Subjects. J. Clin. Diagn. Res. 2017, 11, CC08. [CrossRef]

34. Sun, J.; Jiang, J.; Bao, B.; Wang, S.; He, M.; Zhang, X.; Song, Y. Fabrication of Bendable Circuits on a Polydimethylsiloxane (PDMS) Surface by Inkjet Printing Semi-Wrapped Structures. Materials 2016, 9, 253. [CrossRef]

35. Nag, A.; Afasrimanesh, N.; Feng, S.; Mukhopadhyay, S.C. Strain induced graphite/PDMS sensors for biomedical applications. Sensors Actuators A Phys. 2018, 271, 257-269. [CrossRef]

36. Amjadi, M.; Kyung, K.-U.; Park, I.; Sitti, M. Stretchable, Skin-Mountable, and Wearable Strain Sensors and Their Potential Applications: A Review. Adv. Funct. Mater. 2016, 26, 1678-1698. [CrossRef]

37. Al-Rousan, T.; Schwabkey, Z.; Jirmanus, L.; Nelson, B.D. Health needs and priorities of syrian refugees in camps and urban settings in jordan: Perspectives of refugees and health care providers | Besoins et priorités sanitaires des réfugiés syriens dans les camps et en milieu urbain en jordanie: Perspectives de. East. Mediterr. Health J. 2018, 24, 243-253. [CrossRef] [PubMed]

38. Kelly, C. Respiratory rate 1: Why measurement and recording are crucial. Nurs. Times 2018, 114, $23-24$.

39. Kwak, Y.H.; Kim, J.; Kim, K. Sleep monitoring sensor using flexible metal strain gauge. Jpn. J. Appl. Phys. 2018, 57, 05GD03. [CrossRef]

40. Mathew, J.; Semenova, Y.; Farrell, G. A miniature optical breathing sensor. Biomed. Opt. Express 2012, 3, 3325. [CrossRef] [PubMed]

41. Hamdani, S.; Fernando, A. The Application of a Piezo-Resistive Cardiorespiratory Sensor System in an Automobile Safety Belt. Sensors 2015, 15, 7742-7753. [CrossRef]

(C) 2020 by the authors. Licensee MDPI, Basel, Switzerland. This article is an open access article distributed under the terms and conditions of the Creative Commons Attribution (CC BY) license (http://creativecommons.org/licenses/by/4.0/). 